\title{
Human and Murine Dermis Contain Dendritic Cells Isolation by Means of a Novel Method and Phenotypical and Functional Characterization
}

\author{
Angela Lenz, Martin Heine, Gerold Schuler, and Nikolaus Romani \\ Department of Dermatology, University of Innsbruck, A-6020 Innsbruck, Austria
}

\begin{abstract}
Dendritic cells (DC) comprise a system of cells in lymphoid and nonlymphoid organs that are specialized to present antigens and to initiate primary $T$ cell responses. The Langerhans cell of the epidermis is used as a prototype for studies of $\mathrm{DC}$ in the skin. We have characterized a population of DC in human dermis, one of the first examples of these cells in nonlymphoid organs other than epidermis. To identify their distinct functions and phenotype, we relied upon the preparation of enriched populations that emigrate from organ explants of dermis. The dermal cells have the following key features of mature DC: $(a)$ sheet-like processes, or veils, that are constantly moving; (b) very high levels of surface MHC products; (c) absence of markers for macrophages, lymphocytes, and endothelium; $(d)$ substantial expression of adhesion/costimulatory molecules such as CD11 /CD18, CD54(ICAM-1), B7/BB1, CD40; and (e) powerful stimulatory function for resting $T$ cells. Dermal DC are fully comparable to epidermis-derived $D C$, except for the lack of Birbeck granules, lower levels of CD1a, and higher levels of CD36. DC were also detected in explants of mouse dermis. We conclude that cutaneous DC include both epidermal and dermal components, and suggest that other human nonlymphoid tissues may also serve as sources of typical immunostimulatory DC. (J. Clin. Invest. 1993. 92:2587-2596.) Key words: antigen presenting cell $\bullet$ Langerhans cell • dermis • dendritic cell $\bullet$ immunostimulation
\end{abstract}

\section{Introduction}

Dendritic cells (DC) ${ }^{1}$ constitute a defined system of antigenpresenting cells. They are distributed in many tissues and organs of the body, generally as trace populations (1). Epidermal Langerhans cells (LC) $(1,2)$ are well-studied representatives of this cell system. LC exemplify best how DC are highly specialized to initiate primary immune responses. Freshly isolated LC, which are considered to be in vitro equivalents of resident epidermal LC, are very efficient in processing native protein antigens and generating immunogenic MHC class II-peptide

This work was presented in part at the Arbeitsgemeinschaft Dermatologische Forschung Meeting in Mannheim, Germany, November 9-11, 1990.

Address correspondence to Dr. Nikolaus Romani, Department of Dermatology, University of Innsbruck, Anichstrasse 35, A-6020 Innsbruck, Austria. 1993.

Received for publication 9 March 1993 and in revised form 12 July

1. Abbreviations used in this paper: DC, dendritic cells; LC Langerhans cells.

J. Clin. Invest.

(c) The American Society for Clinical Investigation, Inc.

$0021-9738 / 93 / 12 / 2587 / 10 \$ 2.00$

Volume 92, December 1993, 2587-2596 complexes ( 3 ); at the same time, however, they are poor stimulators of resting $T$ cells (4). Upon culture and under the control of GM-CSF, LC undergo a maturation process whereby they lose the ability to process protein antigens but acquire the capacity to stimulate resting $T$ lymphocytes $(3,4)$. Thus, they seem excellently suited to generate immunity in vivo. DC capture and process antigens in tissues like the skin (immature, "tissue DC"); they undergo the changes observed in vitro and migrate to the draining lymphoid organs; there they present immunogenic MHC-peptide to resting T cells and deliver the necessary signals for an effective $\mathrm{T}$ cell response ( mature, "lymphoid DC") $(1,5)$.

The existence of resident $\mathrm{DC}$ in the dermis, equivalent to epidermal LC, is strongly suggested by several reports (6-11). As opposed to the epidermis, however, dermal DC are not well defined. Several reasons may account for this. Dermal tissue contains many different resident and transiting cell populations that make it more difficult to unequivocally identify and define distinct cell populations by immunohistochemistry. The preparation of dermal cell suspensions is more difficult than the well-established methods to obtain epidermal LC (6). Markers that prove selective for DC/LC in the epidermis (e.g., anti-MHC class II antibodies, ATPase reactivity) are not helpful in the dermal environment because they also stain macrophages and sometimes endothelial cells. Finally, studies on skin sections cannot reveal the unique immunostimulatory features of DC.

Mature DC are the crucial cells for the elicitation of primary immune responses. In contrast to resident, immature "tissue DC," they can be distinguished more easily from other cell types of the myeloid lineage by their distinct morphological, phenotypical, and functional properties. We therefore sought for a way to obtain cultured DC (i.e., mature DC) from the dermis. The recent demonstration that cutaneous DC could be recovered from murine whole skin organ cultures (12) prompted us to modify this method in that we separated epidermis from dermis and evaluated the obtained DC side by side.

\section{Methods}

Mice and media. BALB/c mice were purchased from Charles River Wiga (Sulzfeld, Germany) and used at 6-10 wk of age. The culture medium used for both human and murine experiments was RPMI 1640 (Seromed-Biochrom, Berlin, Germany) supplemented with $10 \%$ FCS (Gibco Laboratories, Paisley, Scotland), $50 \mu \mathrm{M}$ 2-mercaptoethanol (Sigma Chemical Co., St. Louis, MO), $200 \mathrm{mM}$ L-glutamine (Gibco Laboratories), and $20 \mu \mathrm{g} / \mathrm{ml}$ gentamicin (Gibco Laboratories).

Processing of human skin specimens for culture. Normal human skin was obtained from corrective plastic surgery of breast and abdomen. Split-thickness skin was prepared by using a dermatome (DavolSimon, Bard Inc., Sockanosset, MA). It was trimmed to square pieces of $\sim 5 \times 5 \mathrm{~mm}$. The pieces of skin were floated on a solution of the bacterial protease Dispase type II (Boehringer-Mannheim, Mannheim, 
Germany) at a final concentration of $1.2 \mathrm{U} / \mathrm{ml}$ in RPMI 1640 without serum. After $30-40 \mathrm{~min}$ at $37^{\circ} \mathrm{C}$ epidermis and dermis could be pulled apart with the help of fine forceps (13). Dermal and epidermal sheets were rinsed in two changes of RPMI 1640 and placed on $10 \mathrm{ml}$ of culture medium in 100-mm tissue culture petri dishes (Falcon Labware, Oxnard, CA). Epidermal sheets spread and floated when placed dermal side down; dermal sheets coiled up and sank to the bottom of the dish. In some experiments pieces of skin were placed on medium without previous separation of dermis from epidermis. After $2 \mathrm{~d}$ of culture half of the medium was carefully removed and replaced by fresh medium.

Processing of murine skin specimens for culture. Whole mouse ear halves were rinsed with $70 \%$ ethanol, air dried, and treated with dispase as described above. One dermal sheet corresponding to one ear half was cultured in one well of a 24-well tissue culture plate (Falcon Labware) in $2 \mathrm{ml}$ of culture medium. Dorsal dermis could be cultured as a whole. From ventral halves, in contrast, only the relatively small areas that were free of cartilage could be used.

Recovery of human and murine dendritic cells. After 2-5 (routinely 3) d of culture solid tissue remnants were removed from the dishes with forceps and free cells were collected with a pipette, centrifuged once, and counted in the hemocytometer in the presence of trypan blue to assess cell viability. In some experiments recovered human DC were further enriched by passage over dense bovine plasma albumin columns as described $(4,14)$.
Additional methods. All other methods used in this study were done exactly as described previously: immunolabeling for flow cytometry $(14,15)$; immunoperoxidase and immunofluorescence staining of epidermal and dermal sheets (14), cryostat sections (14), and cytocentrifuge smears (16); standard electron microscopy (17); allogeneic mixed leukocyte reaction and oxidative mitogenesis assays $(4,14)$; isolation of slightly $(2-4 \%[18])$ and highly enriched $(30-50 \%[19,20])$ populations of DC from human blood. For functional inhibition studies, hybridoma supernatant of mAb 9.3F10 ( $\mathrm{HB} 180$ from the American Type Culture Collection, Rockville, MD) anti-HLA-DR/DQ was present throughout the time of the assay at a final concentration of $25 \%$ ( vol/vol).

\section{Results}

Recovery of human dermal DC from skin organ culture. After 3 $\mathrm{d}$ of culture a population of $\mathrm{DC}$ as identified by morphological criteria (see below) was recovered from the culture wells. DC could already be observed under phase contrast after 1-2 d. The kinetics of emigration of cells from the dermal explants were not studied in detail, though. Table I shows that in a series of 23 experiments dermal DC appeared consistently in substantial numbers. The degree of enrichment, however, was

Table I. Recovery and Enrichment of Human Dermal DC from Dermal Organ Cultures

\begin{tabular}{|c|c|c|c|c|c|c|c|c|}
\hline \multirow[b]{2}{*}{ Expt. } & \multirow[b]{2}{*}{ Viability* } & \multirow[b]{2}{*}{$\begin{array}{c}\text { Absolute } \\
\text { numbers of } \\
\text { dermal DC }\end{array}$} & \multirow[b]{2}{*}{$\begin{array}{c}\text { Enrichment } \\
\text { of dermal DC }\end{array}$} & \multirow[b]{2}{*}{$\begin{array}{c}\text { Absolute } \\
\text { numbers of } \\
\text { dermal DC }\end{array}$} & & \multicolumn{3}{|c|}{ Low-density fraction after BSA flotation } \\
\hline & & & & & & Viability & $\begin{array}{l}\text { Absolute numbers } \\
\text { of dermal DC }\end{array}$ & $\begin{array}{l}\text { Enrichment } \\
\text { of dermal DC }\end{array}$ \\
\hline & $\%$ & $\times 10^{-6}$ & $\%$ & per $\mathrm{cm}^{2}$ & & $\%$ & $\times 10^{-6}$ & $\%$ \\
\hline 1 & 56 & 3.2 & 2 & 8,000 & $\rightarrow$ & 66 & 2.9 & 12 \\
\hline 2 & 56 & 1.7 & 8 & 9,000 & $\rightarrow$ & 70 & 2.1 & 21 \\
\hline 3 & 57 & 4.2 & 5 & ND & $\rightarrow$ & 69 & 4.5 & 18 \\
\hline 4 & 91 & 6.5 & 18 & ND & $\rightarrow$ & 83 & 3.5 & 31 \\
\hline 5 & 79 & 2.0 & 16 & ND & $\rightarrow$ & 94 & 1.4 & 28 \\
\hline 6 & 60 & 1.2 & 4 & ND & $\rightarrow$ & 76 & 0.5 & 8 \\
\hline 7 & 33 & 0.5 & 3 & 4,000 & $\rightarrow$ & 85 & 0.5 & 8 \\
\hline 8 & 40 & 2.0 & 3 & 11,000 & $\rightarrow$ & 77 & 1.7 & 15 \\
\hline 9 & 66 & 1.5 & 16 & 25,000 & $\rightarrow$ & 90 & 0.85 & 50 \\
\hline 10 & 61 & 8.8 & 5 & 21,000 & $\rightarrow$ & 62 & 4.6 & 11 \\
\hline 11 & 63 & 1.3 & 19 & 11,000 & $\rightarrow$ & 91 & 1.0 & 34 \\
\hline 12 & 54 & 3.0 & 2 & ND & $\rightarrow$ & 68 & 1.5 & 3 \\
\hline 13 & 58 & 1 & 28 & 8,000 & & \multicolumn{3}{|c|}{ No further enrichment } \\
\hline 14 & 82 & 12 & 28 & ND & & \multicolumn{3}{|c|}{ No further enrichment } \\
\hline 15 & 87 & 1.9 & 42 & 32,000 & & \multicolumn{3}{|c|}{ No further enrichment } \\
\hline 16 & 67 & 1.3 & 23 & ND & & \multicolumn{3}{|c|}{ No further enrichment } \\
\hline 17 & 84 & 0.5 & 34 & ND & & \multicolumn{3}{|c|}{ No further enrichment } \\
\hline 18 & 80 & 9.3 & 24 & 23,000 & & \multicolumn{3}{|c|}{ No further enrichment } \\
\hline 19 & 83 & 12.6 & 24 & ND & & \multicolumn{3}{|c|}{ No further enrichment } \\
\hline 20 & 70 & 0.5 & 9 & 4,000 & & \multicolumn{3}{|c|}{ No further enrichment } \\
\hline 21 & 85 & 0.38 & 24 & ND & & \multicolumn{3}{|c|}{ No further enrichment } \\
\hline 22 & 94 & 1.8 & 48 & ND & & \multicolumn{3}{|c|}{ No further enrichment } \\
\hline 23 & 85 & 0.9 & 42 & 8,000 & & \multicolumn{3}{|c|}{ No further enrichment } \\
\hline Means \pm SD & $69 \pm 16$ & & $19 \pm 14$ & $13,600 \pm 9,200$ & & $77 \pm 11$ & & $20 \pm 14$ \\
\hline
\end{tabular}

Recovery of DC from cultures of human dermis explants. Dermal sheets were cultured for 3-4 d; cells released into the culture medium were counted. Dermal DC were identified under the hemocytometer by their characteristic irregular hairy shape. Note that flotation of cells on BSA columns increases both the percentage of dermal DC $(8 \rightarrow 20 \%)$ and the overall viability of cell populations $(60 \rightarrow 77 \%)$. ${ }^{*}$ The percent viable cells of all cells recovered from the culture medium. ${ }^{\ddagger}$ The percentage of dermal DC of all viable cells. ${ }^{\S}$ These numbers are calculated on the basis of the number of 100 -mm petri dishes $\left(\sim 80 \mathrm{~cm}^{2}\right)$ filled with dermal sheets at the start of the culture. It was assumed that $75 \%$ of the petri dish (i.e., $\sim 60 \mathrm{~cm}^{2}$ ) was covered with dermal sheets. 
highly variable (mean, 19\%; range, 2-48\%). Approximately 14,000 (range, 4,000-32,000) dermal DC could be obtained from $1 \mathrm{~cm}^{2}$ of dermis (Table I). The recovery of epidermis-derived DC (i.e., LC) from corresponding epidermal explants (sheets) from the same original pieces of skin was generally lower ( ratio of dermal DC to epidermal DC in 22 experiments: mean, $2.4 \pm 1.7 \mathrm{SD}$; range, 6.0-0.5).

The viability of dermal cell suspensions and the degree of dermal DC enrichment could be increased by flotation on dense bovine serum albumin columns $(4,14)$. In 12 experiments the percentage of dermal DC rose from a mean of $8 \%$ (range, 2-19\%) before flotation to a mean of $20 \%$ (range, 3-50\%; Table I) in the low-density fraction after enrichment. The high-density fraction contained $<10 \%$ of dermal DC loaded onto the column.

To determine whether dermal DC were derived from a pool of proliferating cells either still within the tissue or in the culture medium, split-thickness skin was irradiated with $30 \mathrm{~Gy}$. The number and phenotype of dermal DC collected from the culture medium after $3 \mathrm{~d}$ were not affected by the irradiation treatment (not shown).

Morphology of human dermal dendritic cells. Under phase contrast dermal DC as well as epidermis-derived DC were irregularly shaped and showed prominent cytoplasmic sheet-like processes (Fig. $1 A$ ). Upon close inspection these "veils" were continually extended, retracted, or they showed waving movements. This was identical to cultured epidermal LC or to what had been described for human blood (19) or gut (21) DC. In
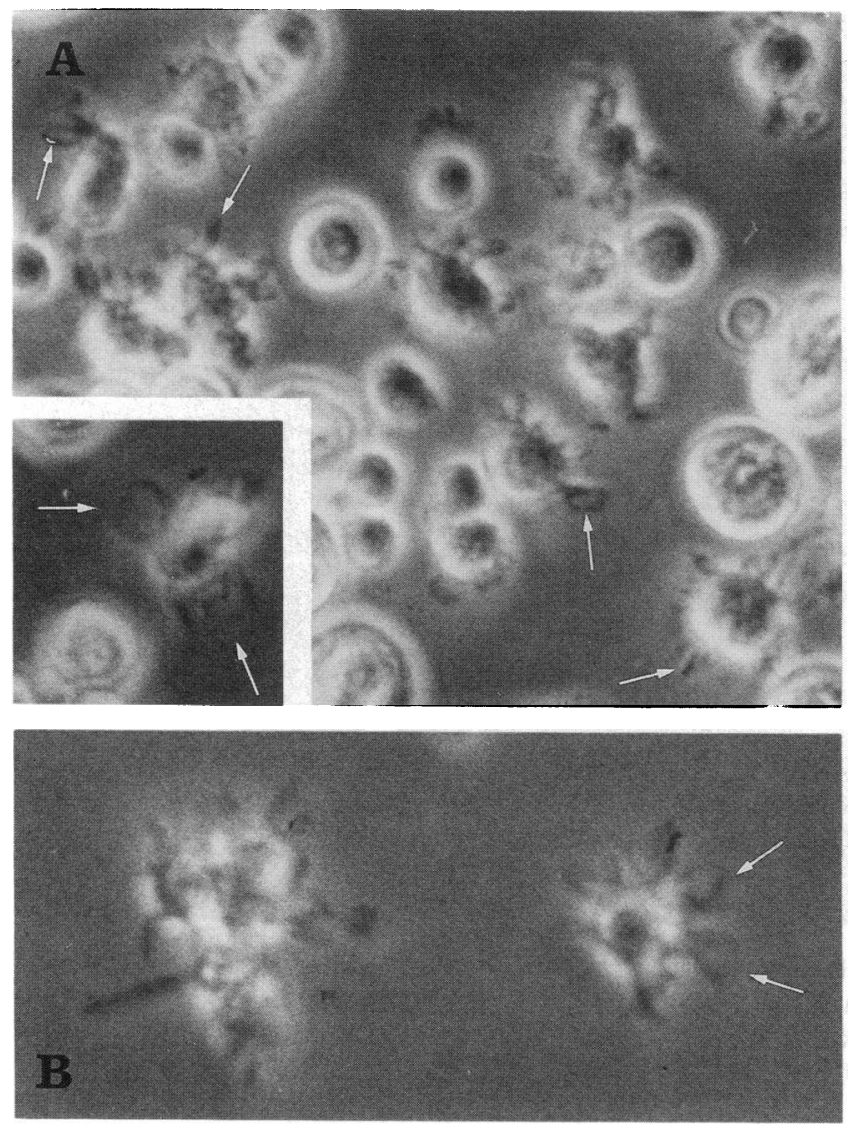

Figure 1. Morphology of human $(A)$ and murine $(B)$ dermal DC. The populations had been enriched before photography. Note the abundance of cytoplasmic sheets ( veils, arrows) $\times 600$. the electron microscope (Fig. 2) these processes or lamellipodia were typically devoid of organelles $(2,22,23)$. Dermal DC did not possess Birbeck granules. In epidermis-derived DC, in contrast, Birbeck granules were found in every cell (not shown). The cytoplasm contained few lysosomes, many mitochondria, profiles of smooth endoplasmic reticulum, and many electron-lucent vacuoles, some of them similar in structure to multivesicular bodies. Finally, flow cytometric analysis of size (forward scatter) and granularity (side scatter) showed that dermal DC had the same large forward scatter profile as human blood $(19,20,24)$ or gut DC (21) (Fig. 3).

Phenotype of human dermal DC. The expression of CD45 and CD33 on the surface of dermal DC proves that they are leukocytes of the myeloid lineage. The hallmark of DC is their abundant expression of MHC class II molecules. Dermal DC express large amounts of MHC class II as demonstrated on cytospin preparations (Fig. 4) and by FACS ${ }^{\circledR}$ (Becton Dickinson \& Co., Mountain View, CA) analyses (Figs. 5 and 6). Dermal DC, epidermis-derived DC (Fig. 4), as well as cultured LC had similar staining intensities. Examination of dermal DC with a large panel of $\mathrm{mAbs}$ revealed an antigenic profile characteristic for DC (summarized in Table II). (a) All MHC and MHC-associated molecules are expressed at high levels. $(b)$ Dermal DC lack lineage-restricted markers such as CD19 and CD20 for B cells, CD3 and CD8 for T cells, and CD14 and CD68 for macrophages. $(c)$ Molecules that are not strictly lineage specific but that, in contrast to monocytes, were found to be present on mature DC $(14,19,24,25)$ are also positive on dermal DC: mAb RFD1 (26), CD5 (27), CD24 (mAb VIBE3) (14), CD25, CD40. (d) Substantial levels of adhesion molecules involved in binding and signaling to $T$ cells $(28)$ in the course of T cell activation (CD11a, CD11c, CD18, CD54 [ICAM-1], B7/BB1) were detected on dermal DC. These key features clearly identify dermal DC as a member of the DC system (1).

Three other markers help to distinguish dermal DC from epidermis-derived DC. Dermal DC are positive for CD1a and CD36 (Fig. 6) and do not stain with mAb Lag (Fig. 4), recognizing a Birbeck granule-associated molecule (29). Epidermisderived DC, in contrast, display an almost inverted profile: CDla expression is uniformly much higher, CD36 is virtually absent (Fig. 6), and Birbeck granules are abundant as visualized by mAb Lag (Fig. 4) and electron microscopy (not shown).

We consistently noticed a subpopulation of dermal DC ( $5-$ $10 \%)$ displaying the epidermal DC phenotype: $\mathrm{CDla}^{+++}$/ Lag $^{+++}$(Figs. 4 and 6). Although the bulk of epidermis, including hair follicles and appendages, could readily be detached from the dermis by means of dispase (13), it was inevitable that tiny pieces of epidermis still remained adherent to the dermal sheet. Therefore, we consider the $\mathrm{CD}_{1} \mathrm{a}^{+++}$/ $\mathrm{Lag}^{+++}$subpopulation as epidermis-derived DC (i.e., LC) contaminating the dermal cell suspension.

$T$ cell stimulatory capacity of human dermal $D C$. Both in the allogeneic mixed leukocyte reaction $(n=6)$ and in an oxidative mitogenesis assay $(n=1)$ dermal DC elicited vigorous proliferative responses in resting $\mathrm{T}$ cells (Fig. 7, $A-C$ ) that could be blocked by the addition of anti-MHC class II antibodies to the culture (Fig. $7 \mathrm{~B}$ ). Dermal DC were as strong as DC derived from the corresponding epidermal sheets, which may be regarded as equivalent to cultured LC (14). While 100-300 dermal DC still induced substantial T cell proliferation (20- 


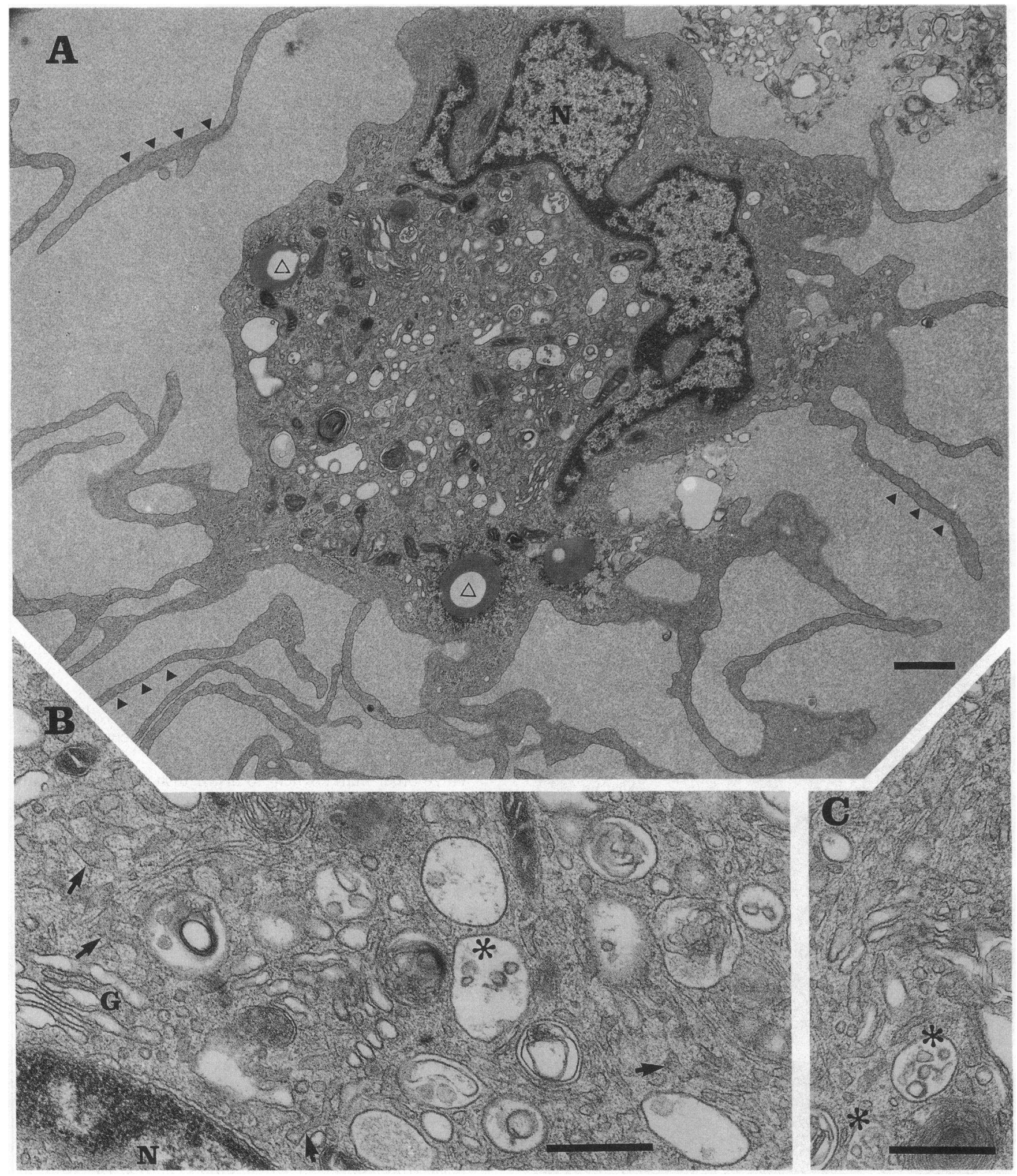

Figure 2. Electron microscopy of human dermal DC derived from a 3-d cultured dermal explant. Note the many cytoplasmic processes devoid of organelles (veils, arrowheads in $A$ ) and the relative paucity of lysosomes and phagosomes. The close ups of the perinuclear region $(B$ and $C$ ) show smooth endoplasmic reticulum (arrows) and multivesicular body-like vacuoles (asterisks). $N$, nucleus; $G$, Golgi apparatus; open triangles, lipid droplets. $\times 11,000(A), \times 38,000(B$ and $C)$; scale bars: $1 \mu \mathrm{m}(A) ; 500 \mathrm{~nm}(B$ and $C)$.

40-fold above background), the same numbers of PBMC from the same donor were inactive (Fig. $7 \mathrm{~A}$ ). At higher doses, however, PBMC did stimulate the T cells. Similar differences in the relative potencies of dermal DC, epidermis-derived DC, and populations of PBMC were found in the oxidative mitogenesis (Fig. 7 C). 

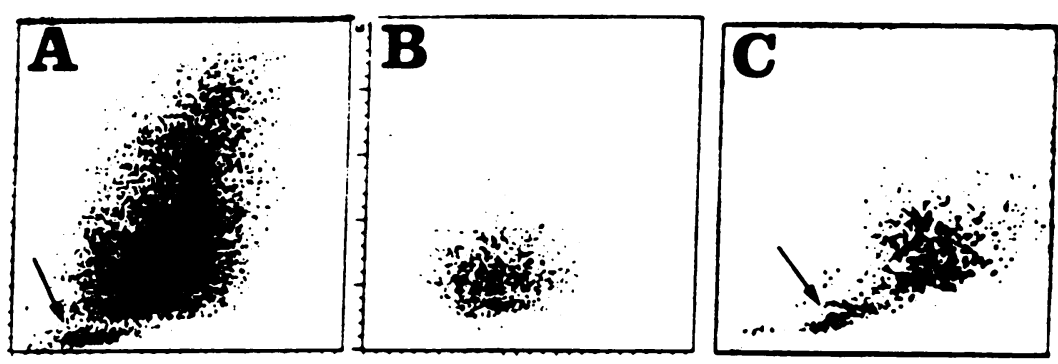

Figure 3. Flow cytometric analysis of human dermal DC from dermal explant cultures $(A$ and $B)$ and of human DC enriched from peripheral blood (19) $(C)$. Cells were labeled with FITC-conjugated anti-MHC class II mAb. Dead cells stained with propidium iodide were excluded from analysis. Dot blots show forward scatter (FSC) on the $x$-axis as a measure of size and side scatter (SSC) on the $y$-axis as a measure of granularity. Whole populations of viable cells are shown in $A$ and $C$; strongly HLA-DR ${ }^{+}$cells (i.e., dermal DC) were selected by gating in $B$. Note that both types of DC have similar FSC/SSC profiles. Contaminating lymphocytes are marked with arrows.
$D C$ in the murine dermis. During culture of whole ear halves for 2-3 d, different cell types emigrated from the skin explants. One of these populations qualified as typical DC by
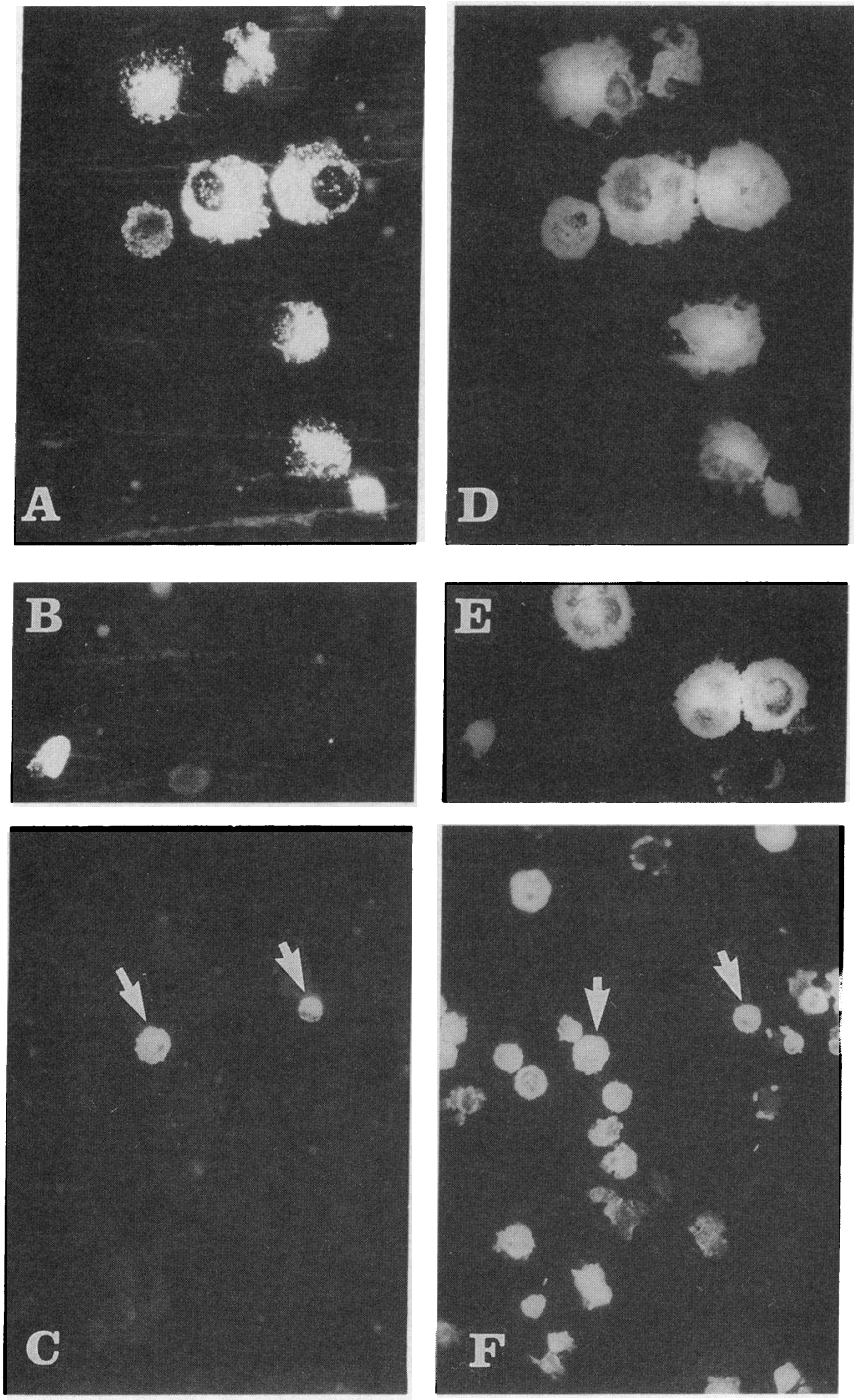

Figure 4. Expression of Birbeck granule-associated Lag antigen (29) by DC derived from 3-d cultured dermal and epidermal explants. Cytospins were double labeled with $\mathrm{mAb}$ anti-Lag $(A-C)$ and antiHLA-DR $(D-F) . A$ and $D, B$ and $E$, and $C$ and $F$ represent identical microscopic fields. Note that all epidermal HLA-DR ${ }^{+}$cells $(D)$, i.e., epidermis-derived DC, display a fine granular Lag staining $(A)$, whereas only a small fraction (arrows) of dermis-derived DC ( $E$ and $F)$ is $\mathrm{Lag}^{+}(B$ and $C$. $) \times 200$. morphology, phenotype, and function as described (12). Similarly, when epidermis and dermis were separated from each other by dispase treatment and were cultured in separate wells, DC populations became evident. Dermis-derived DC could easily be identified and counted under the hemocytometer by virtue of their irregular, hairy shape. In eight experiments the absolute numbers of DC ranged between 5,200 and 32,400 (mean, 13,400 $\pm 9,400 \mathrm{SD}$ ) per mouse. The degree of enrichment was between 18 and $68 \%$ (mean, $43 \pm 18 \%$ SD) of all viable cells. Enrichment of dermal DC by gradients was not attempted. The non-DC in the cultures were not systematically investigated.

Dermal DC possessed long processes ("veils") that were constantly being extended and retracted (Fig. $1 \mathrm{~B}$ ). Their ultrastructural morphology was suggestive for their DC nature: thin cytoplasmic protrusions devoid of organelles (i.e., veils); cytoplasm containing only few lysosomal elements; indented and lobulated nucleus; profiles of smooth endoplasmic reticulum (not shown). Birbeck granules were not found in these cells.

Dermal DC expressed high levels of MHC class II antigens as shown on cytospins (Fig. 8). Additional molecules typical for DC, such as NLDC145 (30) and $\mathrm{mAbs}$ M342 (16) and 2A1 (31), recognizing molecules in distinct organelles of mature DC were expressed. Dermal DC were negative for the macrophage marker $\mathrm{F} 4 / 80$; though few $\mathrm{F} 4 / 80^{+}$macrophages were found in the dermal cell suspensions (Fig. $8 \mathrm{C}$ ).

Dermal DC were potent stimulators of resting $T$ cells in an oxidative mitogenesis assay (Fig. $7 \mathrm{D}$ ). They were at least as powerful as a control population of cultured epidermal LC (4) from the same mouse strain.

\section{Discussion}

DC in nonlymphoid tissues. Epidermal LC (2) have been regarded as the major type of cutaneous DC. So far they have been the best-studied example for DC from nonlymphoid tissues $(1,5)$. Here we report that the dermis also harbors a substantial population of DC as defined by morphological, phenotypical, and functional criteria. In the human system, this is one of the first attempts to isolate DC from a healthy nonlymphoid tissue other than epidermis. The only other human tissues from which immunostimulatory DC were previously obtained are the lamina propria of the gut (21) and lung parenchyma (32). We feel that DC from other nonlymphoid tissues may become more accessible and better studied by using similar simple approaches for isolation as the one described here.

Comparison of dermal DC with DC from other sources. By morphology dermal DC are virtually identical to DC from other sources such as blood and epidermis. Their stimulatory 


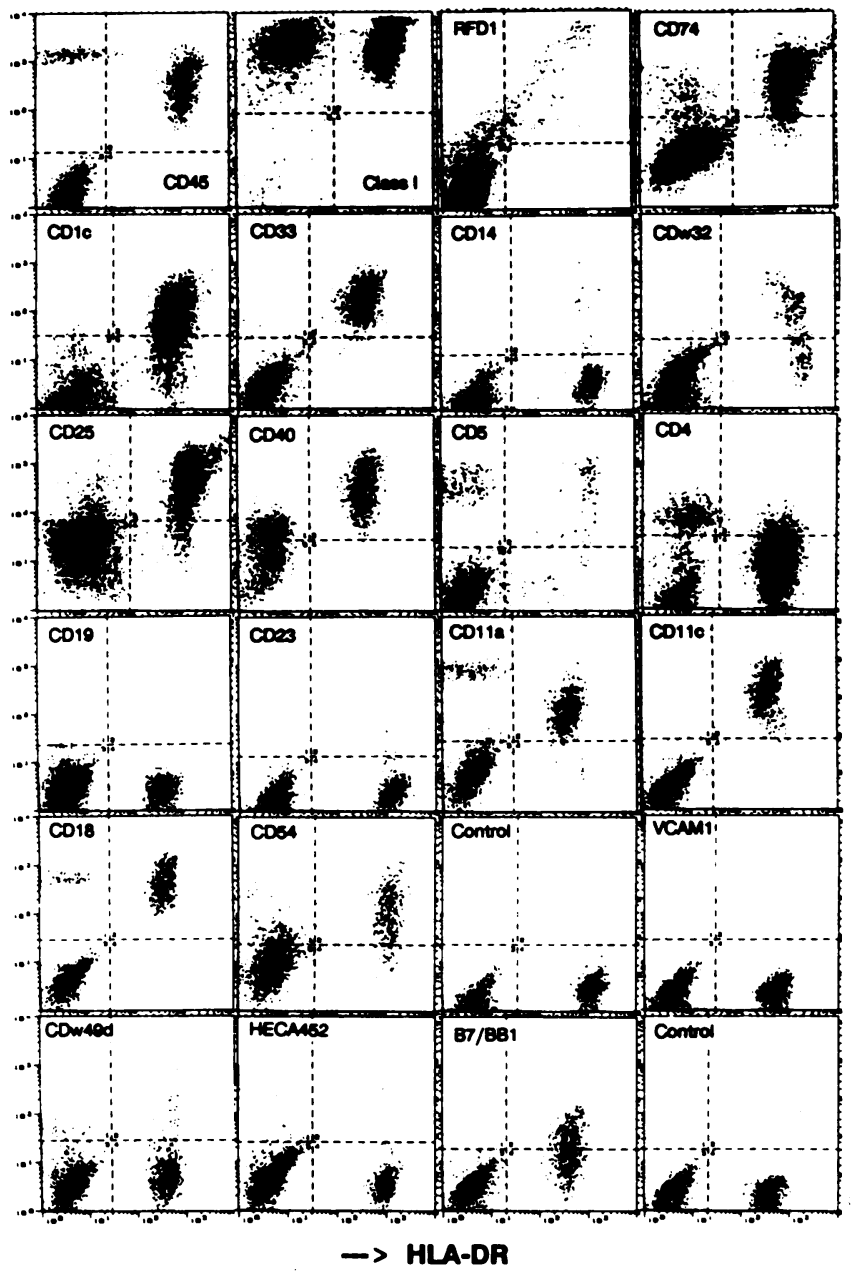

Figure 5. Cytofluorographic analysis of human dermal DC. Dermal DC populations were enriched by flotation on dense BSA columns. Dot plots from different double-labeling experiments are shown; dermal DC were identified by their high expression of HLA-DR antigens (fluorescence on the $x$-axis). The quadrants in each plot were defined on the basis of isotype-matched control antibodies. In addition, controls are explicitely depicted for CD54 (ICAM-1) and B7/BB1. Note that dermal DC express molecules typical for DC (MHC, RFD1, CD25, CD40, CD5, adhesion molecules) but lack or express low levels of macrophage markers (CD14, CDw32). HLA-DR-negative cells expressing CD45, CD5, CD4, CD1 1a, and CD18 are contaminating lymphocytes.

capacity for resting $\mathrm{T}$ cells is as high as described for well-defined types of DC such as cultured LC (4) or blood DC (19). Dermal DC are $\geq 100$ times powerful than blood mononuclear cells of the same donor. Also, the phenotype of dermal DC corresponds exactly to the phenotype of mature human (14, $19,20,24,25,27,33)$ or murine $(15,16,30,31,34) \mathrm{DC}$ from blood or epidermis.

Besides this basal identity our data also demonstrate that there are variants of DC or that DC develop different phenotypical features depending on the milieu where they stem from and where they mature. For example, DC derived from epidermal explant cultures are $\mathrm{CD} 1 \mathrm{a}^{+++} / \mathrm{CD} 36^{-} / \mathrm{Lag}^{+++}$, whereas DC derived from dermal explant cultures are $\mathrm{CDla}^{+} / \mathrm{CD}^{+} 6^{+} /$ $\mathrm{Lag}^{-}$. Interestingly, cultured epidermal LC obtained by standard trypsinization methods express low levels of CDla (14, 25) and human blood DC lack any CD la expression (19). This

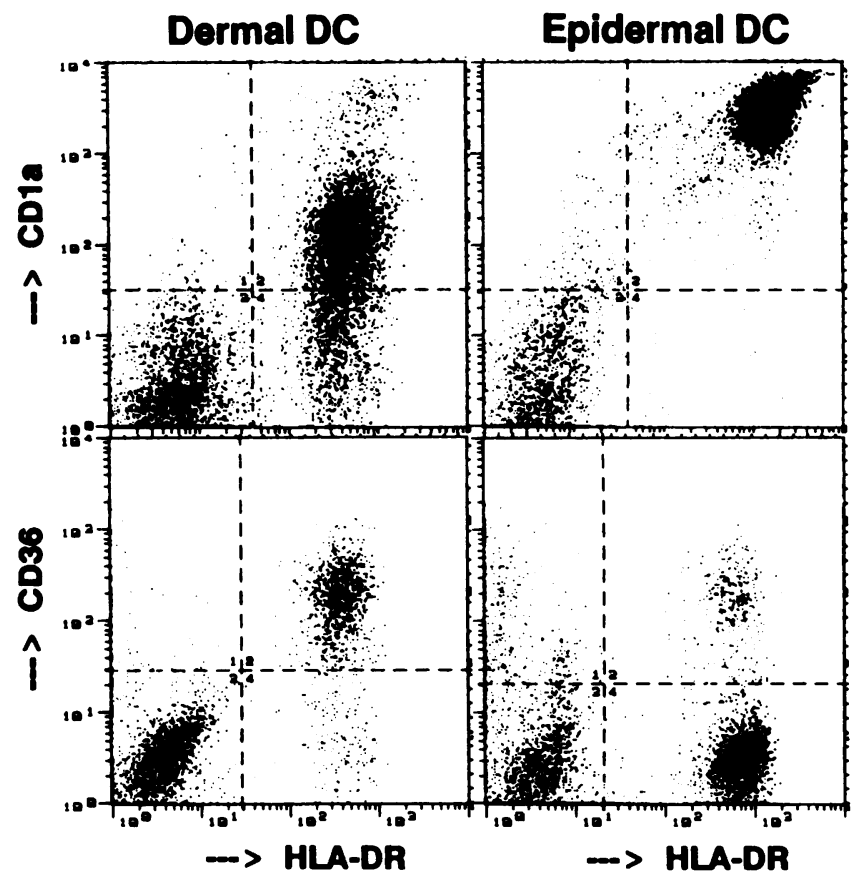

Figure 6. Cytofluorographic analysis of markers distinguishing between human DC derived from either dermis $(l e f t)$ or epidermis $(r i g h t)$. DC are identified by their HLA-DR expression ( $x$-axis). Dermal DC express lower levels of CD1a than epidermis-derived DC (top). The bulk of epidermis-derived DC does not express CD36, whereas dermal DC were consistently positive (bottom). Note the small subset of very strongly CDla-positive dermal DC; they are presumably contaminating epidermis-derived DC.

variability is not surprising as it has been shown that CD1 molecules on LC (35) or monocytes (36) can be modulated by cytokines in vitro. In vivo, Kaplan et al. observed increased numbers of CD1a-expressing cells in the upper dermis in delayed-type hypersensitivity reactions (37) or after intradermal injection of GM-CSF (38). In these experiments the density of epidermal LC remained unchanged (38) or LC were sloughed off through the stratum corneum (37). Therefore, the increase in CD1a-positive dermal cells might also be explained by GMCSF-mediated induction of CDla on resident dermal DC, in addition to recruitment of DC from blood-derived precursors as suggested by the authors.

Relation of dermal $D C$ to dermal dendrocytes and other dermal leukocytes. Dermal DC described here are cells that have been harvested after $3 \mathrm{~d}$ of organ culture. Therefore, caution is warranted when comparing the phenotype of dermal DC to the phenotype of resident, dendritic-appearing cells in the dermis $(9,10,39-42)$. Epidermal LC undergo profound changes $(4,14,25)$ upon a 3-d culture. Likewise, it can be expected that those dermal DC that have emigrated from the dermis explant during the 3-d culture have also changed their morphology and phenotype. Yet, we have attempted to identify the resident dermal cell that may give rise to the dermal DC collected from the culture medium. We immunolabeled cryostat sections and dermal sheets on days 0 and 3 of culture in order to find cells of a particular phenotype that would disappear or be significantly reduced during the culture period, thus allowing us to conclude that these may be the cells from which dermal DC originate. Using a panel of mAbs (HLA-DR, CD1a, CD1c, RFD1, CD36, CD33) we were not able to un- 


\begin{tabular}{|c|c|c|c|c|c|}
\hline \multirow[b]{2}{*}{$\begin{array}{l}\text { CD classification } \\
\text { specificity }\end{array}$} & \multicolumn{2}{|c|}{ Reactivity with DC from: } & \multirow[b]{2}{*}{$\begin{array}{l}\text { Monoclonal } \\
\text { antibodies }\end{array}$} & \multirow[b]{2}{*}{ Source } & \multirow[b]{2}{*}{ Remarks } \\
\hline & $\begin{array}{l}\text { Dermal } \\
\text { explants }\end{array}$ & $\begin{array}{l}\text { Epidermal } \\
\text { explants }\end{array}$ & & & \\
\hline \multicolumn{6}{|l|}{ MHC and associated } \\
\hline HLA-ABC & +++ & +++ & W6/32 & BD & \\
\hline HLA-DR & +++ & +++ & L243 & $\mathrm{BD}$ & \\
\hline HLA-DR + DQ & +++ & +++ & $9.3 \mathrm{~F} 10$ & RMS & \\
\hline HLA-DQ-related & +++ & +++ & RFD1 & LWP & \\
\hline Invariant chain & ++ & ++ & VIC-Y 1 & WK & Intracytoplasmic \\
\hline Invariant chain, CD74 & $\operatorname{tr} /++$ & ND & BU45 & DLH & Cell surface \\
\hline \multicolumn{6}{|l|}{ Leukocyte antigen } \\
\hline CD45 & $++/+++$ & $++/+++$ & HLe & BD & \\
\hline \multicolumn{6}{|l|}{ Macrophage markers } \\
\hline CD14 & - & - & 3C10, LeuM3 & RMS, BD & \\
\hline CD68 & - & ND & EBM 11 & DAKO & \\
\hline \multicolumn{6}{|l|}{ Myeloid markers } \\
\hline $\mathrm{CD} 33$ & $++/+++$ & $++/+++$ & LeuM9 & BD & \\
\hline CD34 & - & - & HPCA-1 & BD & \\
\hline \multicolumn{6}{|l|}{ Receptors } \\
\hline CD23, IgERII & - & ND & BU38 & BS & \\
\hline CD25, IL-2R Low-Aff & $+/++$ & ND & $2 \mathrm{~A} 3$ & $\mathrm{BD}$ & \\
\hline CDw32, FcRII & $-1++$ & $-1++$ & IV.3, CIKM5 & CLA, GP & \\
\hline \multicolumn{6}{|l|}{ T lymphocyte markers } \\
\hline CDla & $-/++$ & +++ & OKT-6 & Ortho & $5-10 \%$ dermal DC +++ \\
\hline CDlc & $\operatorname{tr} /+++$ & $\operatorname{tr} /++$ & L161 & EB & \\
\hline CD3 & - & - & Leu4 & BD & \\
\hline CD4 & $\operatorname{tr} /++$ & $\operatorname{tr} /++$ & Leu $3 a+b$ & BD & $\mathrm{T}$ cells $++/+++$ \\
\hline CD5 & ++ & $\operatorname{tr}$ & Leu 1 & $\mathrm{BD}$ & Weaker than $T$ cells \\
\hline CD8 & - & - & Leu $2 a$ & BD & \\
\hline \multicolumn{6}{|l|}{ B lymphocyte markers } \\
\hline CD19 & - & - & Leu 12 & $\mathrm{BD}$ & \\
\hline $\mathrm{CD} 20$ & - & - & Leu 16 & $\mathrm{BD}$ & \\
\hline $\mathrm{CD} 24$ & + & + & VIB-E3 & WK & \\
\hline CD40 & +++ & +++ & G28-5 & JAL & \\
\hline \multicolumn{6}{|l|}{ Adhesion molecules } \\
\hline CD11a, LFA-1 & $\mathrm{tr} /+++$ & $\operatorname{tr} /++$ & ТВ133 & STP (44) & Lymphocytes +++ \\
\hline CD1lc & $++1+++$ & $\operatorname{tr} /++$ & LeuM5, p150/95 & BD, DAKO & $\cdot$ \\
\hline CD18 & $\operatorname{tr} /+++$ & $\operatorname{tr} /+++$ & CLB54 & STP (44) & Lymphocytes +++ \\
\hline CDw49d, VLA-4 & $\operatorname{tr} /++$ & + & HP2/1 & STP (45) & \\
\hline CD54, ICAM-1 & $\operatorname{tr} /+++$ & $+/+++$ & $7 F 7$ & MPD & \\
\hline $\mathrm{B} 7 / \mathrm{BB} 1$ & $\operatorname{tr} /++$ & $+/++$ & BB1 & $\mathrm{EAC}(46)$ & \\
\hline VCAM-1 & - & - & 4B9, $2 \mathrm{G} 7$ & STP (47), Otsuka & $<20 \%$ epidermal DC ++ \\
\hline ELAM-1 & - & - & $7 A 9$ & Otsuka & \\
\hline HECA452 & - & $-/++$ & HECA-452 & STP (48) & $\sim 25 \%$ epidermal $\mathrm{DC}++/+++$ \\
\hline \multicolumn{6}{|l|}{ Miscellaneous } \\
\hline CD36 & $+/+++$ & $\operatorname{tr} /-$ & OKM-5 & Ortho & \\
\hline Birbeck granule & - & +++ & Lag & MKS (29) & $5-10 \%$ dermal DC +++ \\
\hline Factor XIIIa & - & ND & Rabbit Ig & $\mathrm{BE}$ & \\
\hline
\end{tabular}

Cell surface antigens were investigated by cytofluorometry in most cases; few experiments were done by immunofluorescence on cells attached to poly-L-lysine-coated slides. Levels of $\mathrm{mAb}$ staining are indicated as follows: - , no detectable staining; $\operatorname{tr}$ (trace), $<5 \times$ staining level of isotypematched control;,$+ 5-15 \times$ control;,$++ 15-100 \times$ control;,$+++>100 \times$ control. Division of symbols by a slash indicates a range of staining. Expression of intracellular antigens was determined on cytopsins (invariant chain, Lag, CD68, factor XIIIa). BE, Behring Werke (Marburg/L., Germany); BS, The Binding Site (Birmingham, England); BD, Becton Dickinson \& Co. (Mountain View, CA); Dako Corp. (Glostrup, Denmark); Ortho Pharmaceuticals (Raritan, NJ); Otsuka America Pharmaceutical (Rockville, MD); CLA, C.L. Anderson (Columbus, OH); DLH, D.L. Hardy (Birmingham, England); EAC, E.A. Clark (Seattle, WA); EB, E. Berti (Milano, Italy); JAL, J.A. Ledbetter (Seattle, WA); LWP, L.W. Poulter (London, England); MKS, M. Kashihara-Sawami (Kyoto, Japan); MPD, M.P. Dierich (Innsbruck, Austria); GP, G. Pilkington (Melbourne, Australia); RMS, R.M. Steinman (New York, NY); STP, S.T. Pals (Amsterdam, The Netherlands); WK, W. Knapp (Vienna, Austria); Descriptions of unreferenced mAbs can be retrieved from the Proceedings of the IVth Leukocyte Typing Workshop (49) and/or from reference 14. 

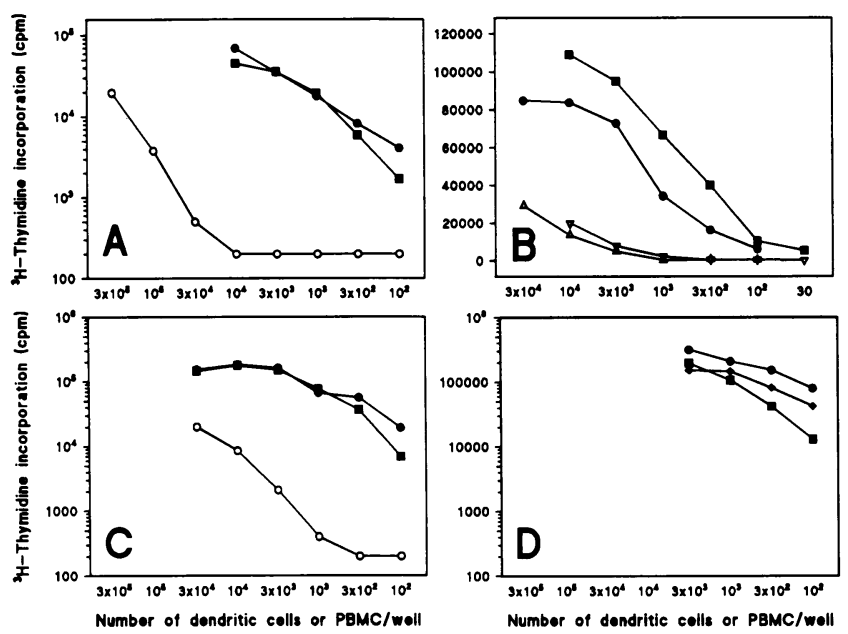

Figure 7. T cell stimulatory function of human $(A-C)$ and murine $(D)$ dermal $\mathrm{DC}$ in the allogeneic mixed leukocyte reaction ( $A$ and $B)$ and in the oxidative mitogenesis assay $(C$ and $D)$. Responder cells are purified $T$ lymphocytes. The following stimulator cell populations were used: filled circles, dermal DC; filled squares, corresponding epidermis-derived DC in $A-C$ and 3-d cultured LC in D; open circles in $A$, PBMC, open circles in $C$, overnight cultured nonadherent PBMC; diamonds in $D$, DC from whole skin explants. Stimulator populations in $A, B$, and $D$ were autologous; PBMC and DC were from different donors in $C$. Note that the stimulatory capacity of dermal DC is strongly inhibited when anti-MHC class II mAbs are present during the assay (triangles in B).

equivocally identify a candidate cell type. The only marker that was reproducibly and significantly reduced after 3-d culture was the factor XIIIa antigen. This molecule characterizes a population of MHC class II-expressing dermal leukocytes, commonly called "dermal dendrocytes" (40). These cells reside predominantly in the upper dermis, partly in a perivascular location. They may be the same cells described by Sontheimer et al. (39) as "dermal perivascular dendritic cells." We were unable to detect factor XIIIa reactivity in isolated dermal DC. Therefore, we could not formally prove that factor XIIIapositive cells had physically left the skin culture; they might as well have lost the expression of that particular molecule. Thus, the resident, probably immature, dermal DC that give rise to the mature dermal DC described here remain to be identified. To this end it will be necessary to dissociate dermal tissue into single-cell suspensions, separate the different cell populations from each other, and study their morphology, phenotype, and function before and after a short-term culture.

Relation of dermal DC to epidermal $L C$. Dermal DC recovered from the medium after $3 \mathrm{~d}$ of organ culture may have three possible origins. (a) They may stem from epidermal LC or their precursors on their way into the epidermis. (b) Alternatively, they may stem from (antigen-laden) epidermal LC on their way from the epidermis to the draining lymph nodes. Cultured human epidermal LC still possess easily detectable Birbeck granules (14). In contrast, human dermal DC were found to be completely devoid of this characteristic organelle. This would argue against a derivation of the bulk of dermal DC from epidermal LC. (c) Finally, the majority of dermal DC may be derived from a resident population of presumably immature DC in the dermis, analogous to the population of LC in the epidermis. The numbers of dermal DC that can be obtained from a given area of skin are in the same order of magnitude (though somewhat less) as the numbers of epidermis-derived DC or cultured LC. On the other hand, immigration and emigration of LC into and from the epidermis under steady-state
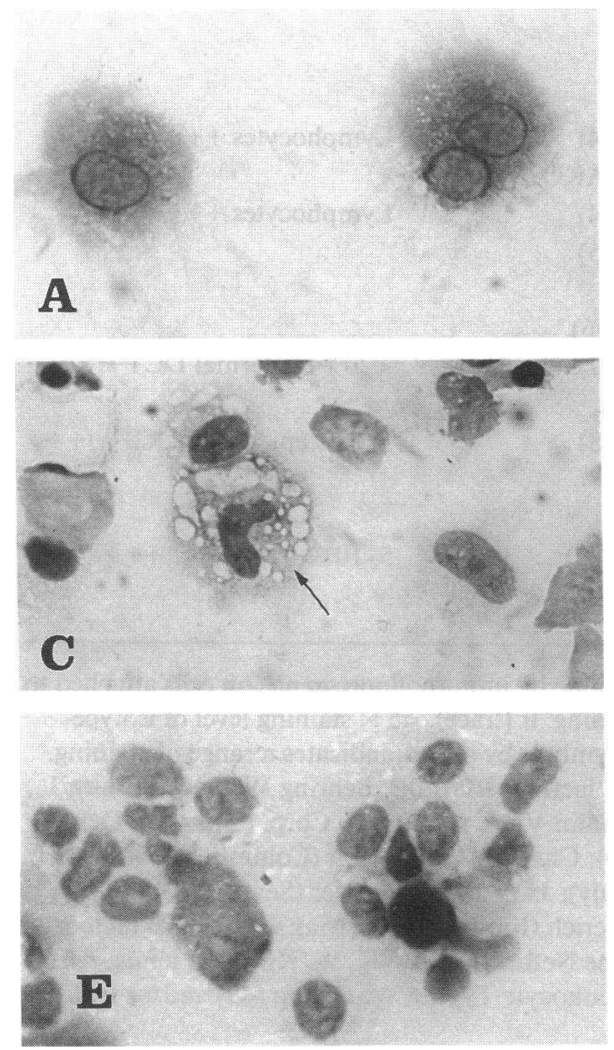
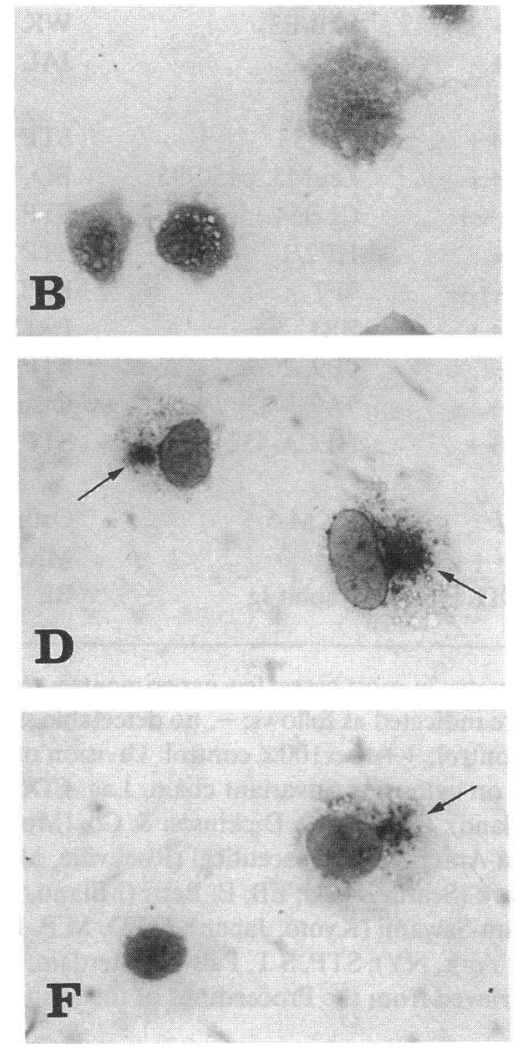

Figure 8. Phenotypical analysis of murine dermal DC on cytospins of cells derived from 3-d cultured dermal explants. Immunoperoxidase staining shows strong expression of MHC class II $(A)$. Dermal DC stain for NLDC-145 $(B)$ but are negative for macrophage antigen $\mathrm{F} 4 / 80(C)$; a rare $\mathrm{F} 4 / 80$-positive contaminating macrophage is arrowed. mAbs $2 \mathrm{Al}(D)$ and $\mathrm{M} 342(F)$ label typical intracytoplasmic granules. Anti$\mathrm{CD} 3$ (hamster mAb 2C11,E) serves as specificity control for M342. Nuclei were counterstained with hematoxilin. $\times 200$. 
conditions is a slow process (43). Therefore, it seems unlikely that dermal DC described here represent only a transiting population. The heterogeneity in phenotype (broad distribution of fluorescence intensities with some markers; see Figs. 5 and 6) would suggest that they may represent DC from all three possible sources.

Evaluation of our method to obtain dermal DC. The method described here is simple and avoids trypsin treatment of dermal tissue. The large variability in DC yields ( see Table I) may be due to differences in donors (young vs. old), in the sources of skin (breast, abdomen, extremities), and in the thickness of the cultured dermal sheet. It should be kept in mind, though, that these populations are likely to be contaminated with small percentages of epidermis-derived DC, i.e., classical LC. In the human system these contaminants are defined by their expression of high levels of CDla and of Lag antigen (i.e., Birbeck granules). In the mouse we did not find a marker that distinguished between DC from dermis and epidermis. Since some hair follicles inevitably remain in the dermal sheet, DC recovered from murine dermal explant cultures probably stem from both dermal and epidermal (i.e., follicular) tissue.

The numbers of epidermal LC obtained by standard trypsinization followed by a 3-d culture together with keratinocytes (14) cannot be accurately compared to dermal DC and epidermis-derived DC numbers. Yet, a rough estimate of cell numbers shows that in the human system the yield of dermal DC $\left(\sim 14,000 / \mathrm{cm}^{2}\right.$; see Table I ) is in the same order of magnitude as the yield of cultured epidermal LC. In one typical experiment $\sim 9,000$ cultured $\mathrm{LC} / \mathrm{cm}^{2}$ of trypsinized epidermis were recovered. Thus, the culture method described here can be used to reliably get substantial numbers of mature DC of dermal origin.

Relevance of dermal DC in disease. Our data show that the dermis is a source of typical DC. They may form an important second line of defence behind epidermal LC. Tasks such as the induction of delayed-type hypersensitivity or the rejection of skin grafts, which epidermal LC were thought to fulfill, may alternatively or additionally be accomplished by dermal DC. In a murine contact hypersensitivity model this has already been demonstrated $(6,8)$.

\section{Acknowledgements}

We are indebted to Prof. Dr. H. Anderl and his staff at the Department of Plastic Surgery for supplying us with skin specimens, to H. Stössel for electron microscopy, and to B. Sickert for expert photographic art work. We are grateful to the many colleagues ( see Table II) who contributed to this study with their gifts of valuable antibodies.

This work was supported by the Austrian Science Foundation (FWF grants P7285MED and P8549MED to G. Schuler).

\section{References}

1. Steinman, R. M. 1991. The dendritic cell system and its role in immunogenicity. Annu. Rev. Immunol. 9:271-296.

2. Schuler, G., N. Romani, H. Stössel, and K. Wolff. 1991. Structural organization and biological properties of Langerhans cells. In Epidermal Langerhans Cells. G. Schuler, editor. CRC Press, Inc., Boca Raton, FL. 87-137.

3. Romani, N., S. Koide, M. Crowley, M. Witmer-Pack, A. M. Livingstone, C. G. Fathman, K. Inaba, and R. M. Steinman. 1989. Presentation of exogenous protein antigens by dendritic cells to $T$ cell clones: intact protein is presented best by immature epidermal Langerhans cells. J. Exp. Med. 169:1169-1178.
4. Schuler, G., and R. M. Steinman. 1985. Murine epidermal Langerhans cells mature into potent immunostimulatory dendritic cells in vitro. J. Exp. Med. 161:526-546.

5. Romani, N., and G. Schuler. 1992. The immunologic properties of epidermal Langerhans cells as a part of the dendritic cell system. Springer Semin. Immunopathol. 13:265-279.

6. Tse, Y., and K. D. Cooper. 1990. Cutaneous dermal Ia ${ }^{+}$cells are capable of initiating delayed type hypersensitivity responses. J. Invest. Dermatol. 94:267272.

7. Cooper, K. D., N. Duraiswamy, S. Kang, J. Crespo, and W. Lee. 1987. Murine dermal cell suspensions contain $\mathrm{T}$ cell activating antigen-presenting cells. J. Invest. Dermatol. 88:482a. (Abstr.)

8. Streilein, J. W. 1989. Antigen-presenting cells in the induction of contact hypersensitivity in mice: evidence that Langerhans cells are sufficient but not required. J. Invest. Dermatol. 93:443-448.

9. Weber-Matthiesen, K., and W. Sterry. 1990. Organization of the monocyte/macrophage system of normal human skin. J. Invest. Dermatol. 95:83-89.

10. Murphy, G. F., D. Messadi, E. Fonferko, and W. W. Hancock. 1986. Phenotypic transformation of macrophages to Langerhans cells in the skin. Am. J. Pathol. 123:401-406.

11. Murphy, G. F., B. R. Bronstein, R. W. Knowles, and A. K. Bhan. 1985. Ultrastructural documentation of M241 glycoprotein on dendritic and endothelial cells in normal human skin. Lab. Invest. 52:264-269.

12. Larsen, C. P., R. M. Steinman, M. Witmer-Pack, D. F. Hankins, P. J. Morris, and J. M. Austyn. 1990. Migration and maturation of Langerhans cells in skin transplants and explants. J. Exp. Med. 172:1483-1493.

13. Kitano, Y., and N. Okada. 1983. Separation of the epidermal sheet by dispase. Br. J. Dermatol. 108:555-560.

14. Romani, N. A., Lenz, H. Glassel, H. Stössel, U. Stanzl, O. Majdic, P. Fritsch, and G. Schuler. 1989. Cultured human Langerhans cells resemble lymphoid dendritic cells in phenotype and function. J. Invest. Dermatol. 93:600609.

15. Crowley, M. T., K. Inaba, M. Witmer-Pack, and R. M. Steinman. 1989. The cell surface of mouse dendritic cells: FACS analyses of dendritic cells from different tissues including thymus. Cell. Immunol. 118:108-125.

16. Agger, R., M. Witmer-Pack, N. Romani, H. Stössel, W. J. Swiggard, J. P. Metlay, E. Storozynsky, P. Freimuth, and R. M. Steinman. 1992. Two populations of splenic dendritic cells detected with M342, a new monoclonal to an intracellular antigen of interdigitating dendritic cells and some B lymphocytes. $J$. Leukocyte Biol. 52:34-42.

17. Stössel, H., F. Koch, E. Kämpgen, P. Stöger, A. Lenz, C. Heufler, N. Romani, and G. Schuler. 1990. Disappearance of certain acidic organelles (endosomes and Langerhans cell granules) accompanies loss of antigen processing capacity upon culture of epidermal Langerhans cells. J. Exp. Med. 172:14711482.

18. Van Voorhis, W. C., L. S. Hair, R. M. Steinman, and G. Kaplan. 1982. Human dendritic cells. Enrichment and characterization from peripheral blood. J. Exp. Med. 155:1172-1187.

19. Freudenthal, P. S., and R. M. Steinman. 1991. The distinct surface of human blood dendritic cells, as observed after an improved isolation method. Proc. Natl. Acad. Sci. USA. 87:7698-7702.

20. Young, J. W., L. Koulova, S. A. Soergel, E. A. Clark, R. M. Steinman, and B. Dupont. 1992. The B7/BB1 antigen provides one of several costimulatory signals for the activation of $\mathrm{CD} 4{ }^{+} \mathrm{T}$ lymphocytes by human blood dendritic cells in vitro. J. Clin. Invest. 90:229-237.

21. Pavli, P., D. A. Hume, E. Van de Pol, and W. F. Doe. 1993. Dendritic cells, the major antigen-presenting cells of the human colonic lamina propria. Immunology. 78:132-141.

22. Steinman, R. M., and Z. A. Cohn. 1973. Identification of a novel cell type in peripheral lymphoid organs of mice. I. Morphology, quantitation, tissue distribution. J. Exp. Med. 137:1142-1162.

23. Steinman, R. M., G. Schuler, N. Romani, and G. Kaplan. 1988. Dendritic Cells. In Atlas of Blood Cells: Function and Pathology, vol. 1. D. Zucker-Franklin, M. F. Greaves, C. E. Grossi, and A. M. Marmont, editors. Edi. Ermes and Lea \& Febiger, Milano, Philadelphia. 361-377.

24. Thomas, R., L. S. Davis, and P. E. Lipsky. 1993. Isolation and characterization of human peripheral blood dendritic cells. J. Immunol. 150:821-834.

25. Teunissen, M. B. M., J. Wormmeester, S. R. Krieg, P. J. Peters, I. M. C. Vogels, M. L. Kapsenberg, and J. D. Bos. 1990. Human epidermal Langerhans cells undergo profound morphological and phenotypical changes during in vitro culture. J. Invest. Dermatol. 94:166-173.

26. Poulter, L. W., D. A. Campbell, C. Munro, and G. Janossy. 1986. Discrimination of human macrophages and dendritic cells by means of monoclonal antibodies. Scand. J. Immunol. 24:351-357.

27. Wood, G. S., and P. S. Freudenthal. 1992. CD5 monoclonal antibodies react with human peripheral blood dendritic cells. Am. J. Pathol. 141:789-795.

28. Steinman, R. M., and J. W. Young. 1991. Signals arising from antigenpresenting cells. Curr. Opin. Immunol. 3:361-372.

29. Kashihara, M., M. Ueda, Y. Horiguchi, F. Furukawa, M. Hanaoka, and S. 
Imamura. 1986. A monoclonal antibody specifically reactive to human Langerhans cells. J. Invest. Dermatol. 87:602-612.

30. Kraal, G., M. Breel, M. Janse, and G. Bruin. 1986. Langerhans' cells, veiled cells, and interdigitating cells in the mouse recognized by a monoclonal antibody. J. Exp. Med. 163:981-997.

31. Inaba, K., M. Inaba, N. Romani, H. Aya, M. Deguchi, S. Ikehara, S. Muramatsu, and R. M. Steinman. 1992. Generation of large numbers of dendritic cells from mouse bone marrow cultures supplemented with granulocyte/ macrophage colony-stimulating factor. J. Exp. Med. 176:1693-1702.

32. Nicod, L. P., M. F. Lipscomb, J. C. Weissler, and G. B. Toews. 1989. Mononuclear cells from human lung parenchyma support antigen-induced $\mathrm{T}$ lymphocyte proliferation. J. Leukocyte Biol. 45:336-344.

33. Young, J. W., and R. M. Steinman. 1988. Accessory cell requirements for the mixed-leukocyte reaction and polyclonal mitogens, as studied with a new technique for enriching blood dendritic cells. Cell. Immunol. 111:167-182.

34. Larsen, C. P., S. C. Ritchie, T. C. Pearson, P. S. Linsley, and R. P. Lowry. 1992. Functional expression of the costimulatory molecule, B7/BB1, on murine dendritic cell populations. J. Exp. Med. 176:1215-1220.

35. Walsh, L. J., G. J. Seymour, and R. N. Powell. 1986. Modulation of gingival Langerhans cell T6 antigen expression in vitro by interleukin 1 and an interleukin 1 inhibitor. Clin. Exp. Immunol. 64:334-341.

36. Kasinrerk, W., T. Baumruker, O. Majdic, W. Knapp, and H. Stockinger. 1993. CDI molecule expression on human monocytes induced by granulocytemacrophage colony-stimulating factor. J. Immunol. 150:579-584.

37. Kaplan, G., S. Laal, G. Sheftel, A. Nusrat, I. Nath, N. K. Mathur, R. S. Mishra, and Z. A. Cohn. 1988. The nature and kinetics of a delayed immune response to purified protein derivative of tuberculin in the skin of lepromatous leprosy patients. J. Exp. Med. 168:1811-1824.

38. Kaplan, G., G. Walsh, L. S. Guido, P. Meyn, R. A. Burkhardt, R. M. Abalos, J. Barker, P. A. Frindt, T. T. Fajardo, R. Celona, and Z. A. Cohn. 1992 Novel responses of human skin to intradermal recombinant granulocyte/macrophage-colony-stimulating factor: Langerhans cell recruitment, keratinocyte growth, and enhanced wound healing. J. Exp. Med. 175:1717-1728.

39. Sontheimer, R. D., T. Matsubara, and L. L. Seelig, Jr. 1989. A macro- phage phenotype for a constitutive, class II antigen-expressing, human dermal perivascular dendritic cell. J. Invest. Dermatol. 93:154-159.

40. Cerio, R., C. E. M. Griffiths, K. D. Cooper, B. J. Nickoloff, and J. T. Headington. 1989. Characterization of factor XIIIa positive dermal dendritic cells in normal and inflamed skin. Br. J. Dermatol. 121:421-431.

41. Nickoloff, B. J. 1991. The human progenitor cell antigen (CD34) is localized on endothelial cells, dermal dendritic cells, and perifollicular cells in formalin-fixed normal skin, and on proliferating endothelial cells and stromal spindleshaped cells in Kaposi's sarcoma. Arch. Dermatol. 127:523-529.

42. Wang, B., A. Rieger, O. Kilgus, K. Ochiai, D. Maurer, D. Födinger, J.-P. Kinet, and G. Stingl. 1992. Epidermal Langerhans cells from normal human skin bind monomeric IgE via FceRI. J. Exp. Med. 175:1353-1365.

43. Fossum, S. 1989. Dendritic leukocytes: features of their in vivo physiology. Res. Immunol. 140:883-891.

44. Scheeren, R. A., G. Koopman, S. Van der Baan, C. J. L. M. Meijer, and S. T. Pals. 1991. Adhesion receptors involved in clustering of blood dendritic cells and T lymphocytes. Eur. J. Immunol. 21:1101-1105.

45. Sanchez-Madrid, F., M. O. Landazuri, G. Morago, M. Cebrian, A. Acevedo, and C. Bernabeu. 1986. VLA-3: A novel polypeptide association within the VLA molecular complex: cell distribution and biochemical characterization. Eur. J. Immunol. 16:1343-1349.

46. Yokochi, T., R. D. Holly, and E. A. Clark. 1982. B lymphoblast antigen (BB-1) expressed on Epstein-Barr virus activated B cell blasts, B lymphoid lines, and Burkitt's lymphomas. J. Immunol. 128:823-827.

47. Carlos, T. M., B. R. Schwartz, N. L. Kovach, E. Yee, M. Rosso, L. Osborn, G. Chi-Rosso, B. Newman, R. Lobb, and J. M. Harlan. 1986. Vascular cell adhesion molecule-1 mediates lymphocyte adherence to cytokine-activated cultured human endothelial cells. Blood. 76:965-970.

48. Duijvestijn, A. M., E. Horst, S. T. Pals, B. N. Rouse, A. C. Steere, L. J. Picker, C. J. L. M. Meijer, and E. C. Butcher. 1988. High endothelial differentiation in human lymphoid and inflammatory tissues defined by monoclonal antibody HECA-452. Am. J. Pathol. 130:147-155.

49. Knapp, W., W. R. Gilks, R. E. Schmidt, E. P. Rieber, and A. E. G. Kr. von dem Borne, editors. 1989. Leukocyte Typing IV: White Cell Differentiation Antigens. Oxford University Press, Oxford. 1182 pp. 